\title{
Caregivers' knowledge of pneumonia and uptake of vaccination in under-five children in Kaduna State, Nigeria
}

\author{
A. K. Yahaya ${ }^{1}$, B. N. Ekpenyong ${ }^{2}$ and P. Obegu $^{3}$ \\ 1,2,3 Department of Public Health, University of Calabar, Nigeria
}

Pneumonia, though very much a preventable disease, still remains a tangible threat to the lives of under-5 children. Caregivers' knowledge of pneumonia is important in effective management. The study determined the reported proportion of childhood pneumonia in Kaduna State and assessed caregivers' knowledge of pneumonia and uptake of pneumococcal vaccine among under- 5 children. The mixed method research approach used 500 caregivers of under-five children in urban and rural communities in Kaduna state. Ethical approval and informed consent of participants was obtained before data collection using a pre-tested semistructured questionnaire and a focus group discussion guide. Chi-square statistical test was used to test for association between variables, while data from the focus group discussion was analyzed using thematic coding process. Most respondents were aware of pneumonia, they had local names for it but majority 340 $(68 \%)$ had poor knowledge of pneumonia. The overall occurrence of pneumonia as reported by respondents among under-five children was $33(6.6 \%)$. The rate of child pneumococcal vaccine uptake as reported by respondents was $105(21 \%)$, the uptake was significantly more among the urban dwellers $(p<0.01)$. The knowledge of pneumonia and uptake of pneumococcal vaccination was poor. Routine and constant health education of the community members on pneumonia is very necessary to preserve lives of under- 5 children in our communities.

Journal of Medical and Biomedical Sciences (2018) 7(1), 40 - 48

Keywords: Pneumonia, Caregivers, Under-5-children, knowledge, Vaccination

\section{INTRODUCTION}

Pneumonia is a severe form of acute lower respiratory tract infection and is the leading cause of death in children under five years of age worldwide, causing more child deaths than any other disease (WHO, 2016). Despite substantial increase in the understanding of the clinical syndrome of pneumonia and its etiologies, its accurate diagnosis is challenging when clinical indicators are relied on, and improves only modestly with addition of laboratory, microbiological, or radiological tests (Stöppler, 2016).

Reliably identifying the causes of bacteria among children and differentiating between bacterial and non-bacterial causes still remain a challenge as the knowledge gap in this regard is a far-cry from

Correspondence: Aperki Kono Yahaya, Department of Public Health, University of Calabar, Nigeria

Email: aperkiyahaya@gmail.com increasing (Grimwood et al., 2016). Pneumonia still remains the single largest infectious cause of death in children worldwide, as it accounts for 16 percent of all deaths of children under five years old (WHO, 2016). Pneumonia is the most serious outcome of acute respiratory infection in young children in Nigeria (National Population Commission (NPC) (NPC, 2006). In fact, it was established that pneumonia claims the lives of about 195,000 Nigerian children annually, while about 124,000 others die of diarrhea (Madugba, 2015).

Children and infants are presumed to have pneumonia if they exhibit a cough and fast or difficult breathing. Caregivers therefore have an important role to play in recognizing the symptoms and danger signs of pneumonia in children and seeking appropriate medical care as necessary, thereby averting pneumonia deaths (Tuhebwe et al., 2014). Attitude, practices and health seeking behavior of caregivers play a huge role on the health status of children, who are known to be dependents 


\section{Under-five caregivers' knowledge of Pneumonia}

Yahaya et al.,

as they are incapable of taking care of themselves (Thandar et al., 2015).

To reduce the morbidity and mortality associated with pneumonia infections, Nigeria introduced free pneumococcal vaccine for children under five years in 2014 with support from international funding agencies (Wiwa and Ojumu, 2016). Despite this efforts, pneumonia remains the most common cause of childhood mortality, especially in the northern part of Nigeria that has low uptake of vaccination in children (Gidado et al., 2014).

It is therefore important to determine caregivers' knowledge of pneumonia, which is particularly necessary for early treatment seeking and appropriate use of health care options, as well as catering to the medical needs of the children. Promoting awareness and prevention through research and advocacy could go a long way in improving the access to healthcare and quality of life at the community level.

\section{MATERIALS AND METHODS Study design}

The study was a community based descriptive cross-sectional study that determined the caregivers' knowledge and health seeking behavior on pneumonia in under-five children in selected Local Government Areas (LGAs) of Kaduna State, Nigeria, using both quantitative and qualitative methods of data collection. Kaduna state, is located in the northwestern parts of Nigeria and being the third most populous state in the country (National Population Commission, 2006), has lots of communities that are densely populated, with its peculiar climatic conditions such as strong harmattan which increases the risk of infection, and numerous industries whose fumes contribute to air pollution known to be significantly responsible for several pulmonary diseases worldwide (Obinna, 2015).

\section{Sample size determination for respondents}

The sample size of respondents used for this study was obtained using the Kish (1965) formula for cross-sectional studies given as: $\quad \mathrm{n}=\frac{\mathrm{Z}^{2} \mathrm{pq}}{\mathrm{d}^{2}}$
Using a $23 \%$ prevalence of pneumonia from a previous study (Roca et al., 2012), 4\% precision at $95 \%$ confidence interval and considering 20\% non-response rate gave a sample size of 531 .

\section{Sampling procedure}

A multistage sampling technique was used to select the respondents, who were caregivers of under-five children in this study, from the LGA level down to the household level. The 23 LGAs in Kaduna state were stratified based on urbanization (urban and rural) and simple random sampling by lottery method was used to select one LGA each from the two strata (urban and rural) that were used for the study.

A list of all the wards for each of the two selected LGAs was used to constitute a sampling frame. Three wards each from both the urban and rural LGAs were randomly selected, resulting in a total of six selected wards (3 urban and 3 rural), two communities and four streets were selected from each ward resulting 48 streets. Eleven households with under-five children were selected using systematic random sampling method from each of the 48 selected streets. Only households with under -five children were selected for the study. The caregiver of the under-fiver child, male or female was selected for the study. A pre-tested semi structured questionnaire was designed and used to elicit data from the respondents.

\section{Sampling procedure for focus group discussions (FGDs)}

Focus group discussion participants were purposively sampled from a different but homogenous group of caregivers besides those who responded to the questionnaires. Eight participants constituted a group, making up two focus group discussions per LGA. A pre-tested FGD guide comprising of seven predetermined open-ended questions was used for the sessions.

\section{Method for data analysis}

The quantitative data generated from this study was analysed using the Microsoft Excel 2016 and Statistical Package for Social Sciences (SPSS) 
Under-five caregivers' knowledge of Pneumonia Yahaya et al.,

software version 20. Frequency distribution tables and figures were used to describe the data, while chi-square statistics was the test used for the comparison of proportions and testing of association. For the qualitative data analysis, tape-recorded data was transcribed and translated into English in the sessions where FGD is conducted in local language. The responses were manually analyzed using thematic coding method.

\section{Ethical consideration}

An ethical clearance permission from the Kaduna State Ministry of Health's Research Ethics Committee, was obtained before commencement of the study. Informed verbal consent was sought from study participants before participation in the study. All information about the respondents were handled with utmost confidentiality and used only for intended purposes.

\section{RESULTS}

Socio-demographic profile of household respondents

A total of 500 fully completed questionnaires were recovered and analysed giving a response rate of $94.2 \%$. Majority of caregivers in this study were females $338(67.6 \%)$. For age, most of the caregivers $205(42 \%)$ were between the ages of $26-35$ years while the least age group was 56 years and above. More than three quarter of the respondents in this study were married $431(86.2 \%)$, while $41(8.2 \%)$ were single. Majority of respondents in this study had tertiary education 298 (59.6\%). Majority of the children in this study were also females 259 (51.8\%). Most of the children in this study were less than a year old $176(35.2 \%)$ (Table1).

In this study, the overall occurrence of pneumonia as reported by respondents among under-five children was $33(6.6 \%), 20(8 \%)$ occurred in the rural while $13(5.2 \%)$ occurred in the urban LGAs (Figure 1). Majority of respondents in this study were aware of pneumonia as a disease condition 386 $(77.2 \%)$. Most of the participants were of the opinion that pneumonia was caused by cold temperature/weather change 335 (67\%), followed by bacteria 118 (23.6\%), germs 109 (21.8\%), viruses 43
Table 1 Socio demographic characteristics of respondents

\begin{tabular}{|c|c|}
\hline Variables & Frequency (\%) \\
\hline \multicolumn{2}{|l|}{ Gender of caregiver } \\
\hline Male & $162(32.4 \%)$ \\
\hline Female & $338(67.6 \%)$ \\
\hline \multicolumn{2}{|l|}{ Age of caregiver } \\
\hline Less than 25 years & $141(28.2 \%)$ \\
\hline $26-35$ years & $217(43.4 \%)$ \\
\hline $36-45$ years & $108(21.6 \%)$ \\
\hline $46-55$ years & $31(6.2 \%)$ \\
\hline 56 years and older & $3(0.6 \%)$ \\
\hline \multicolumn{2}{|l|}{ Marital status } \\
\hline Married & $431(86.2 \%)$ \\
\hline Single & $41(8.2 \%)$ \\
\hline Widowed & $10(2.0 \%)$ \\
\hline Separated & $12(2.4 \%)$ \\
\hline Divorced & $6(1.2 \%)$ \\
\hline \multicolumn{2}{|l|}{ Educational status } \\
\hline No formal education & $17(3.4 \%)$ \\
\hline Primary & $36(7.2 \%)$ \\
\hline Secondary & $149(29.8 \%)$ \\
\hline Tertiary & $298(59.6 \%)$ \\
\hline \multicolumn{2}{|l|}{ Occupation } \\
\hline Unemployed & $74(14.8 \%)$ \\
\hline Self employed & $124(24.8 \%)$ \\
\hline Formal employment & $183(36.6 \%)$ \\
\hline Casual labourer & $24(4.8 \%)$ \\
\hline Farmer & $81(16.2 \%)$ \\
\hline \multicolumn{2}{|l|}{ Monthly income } \\
\hline Below N18,000 & $98(19.6 \%)$ \\
\hline N18,000 - N50,000 & $161(32.2 \%)$ \\
\hline N51,000 - N100,000 & $156(31.2 \%)$ \\
\hline Above N100,000 & $81(16.2 \%)$ \\
\hline \multicolumn{2}{|l|}{ Religion } \\
\hline Christianity & $279(55.8 \%)$ \\
\hline Islam & $221(44.2 \%)$ \\
\hline \multicolumn{2}{|c|}{ Children aged 5 and below in household } \\
\hline One & $163(32.6 \%)$ \\
\hline Two & $174(34.8 \%)$ \\
\hline Three & $85(17.0 \%)$ \\
\hline Four & $78(15.6 \%)$ \\
\hline \multicolumn{2}{|l|}{ Age of child } \\
\hline Less than one year & $176(35.2 \%)$ \\
\hline $1-2$ years & $126(25.2 \%)$ \\
\hline $2-3$ years & $90(18.0 \%)$ \\
\hline $3-4$ years & $55(11.0 \%)$ \\
\hline $4-5$ years & $53(10.6 \%)$ \\
\hline \multicolumn{2}{|l|}{ Gender of child } \\
\hline Male & $241(48.2 \%)$ \\
\hline Female & $259(51.8 \%)$ \\
\hline
\end{tabular}


Under-five caregivers' knowledge of Pneumonia

Yahaya et al.,

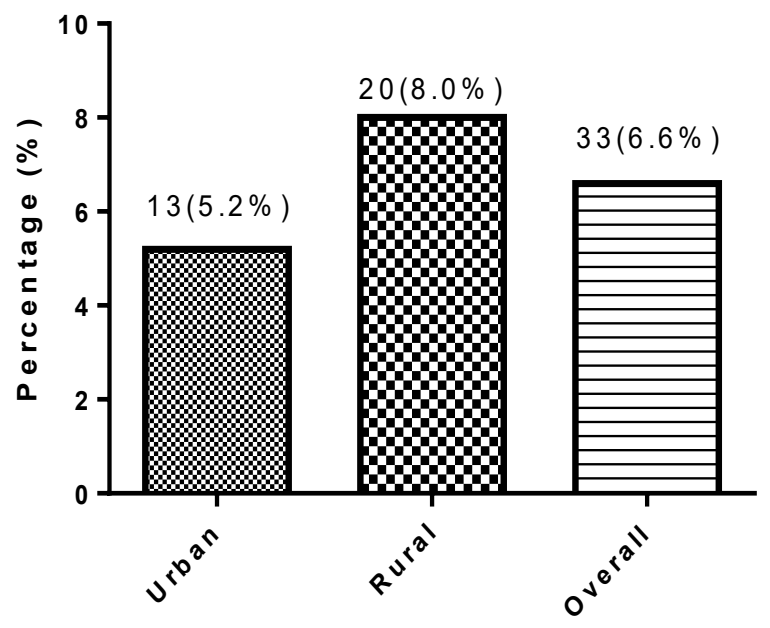

Figure. 1: Occurrence of childhood pneumonia as reported by caregivers in the selected urban and rural communities in Kaduna state

(8.6\%), fungi $23(2.3 \%)$. Some respondents were also of the opinion that pneumonia was caused by witchcraft $13(2.6 \%)$.

The responses to the questions on knowledge of pneumonia in under-five children were scored individually to arrive at each respondent's score as shown in Table 2. The total scores range from zero to 40 . Score range of $0-10$ represented poor knowledge of pneumonia in under-five children, score range $11-20$ represented fair knowledge of pneumonia in under-five children, score range of 21 - 30 represented good knowledge of pneumonia in under-five children while score range of $31-40$ represented excellent knowledge of pneumonia in under-five children. Majority of respondents 340 $(68 \%)$ had poor knowledge of pneumonia in underfive children while $95(19 \%)$ had fair knowledge of pneumonia in under-five children and the few remaining had good $30(6 \%)$ and excellent $35(7 \%)$ knowledge of pneumonia in under-five children (Figure 2).

Majority of the respondents 18 (54.5\%) who reported that their child had pneumonia had poor knowledge level regarding the causes, sign and symptom and preventive measures to childhood
Table 2 Caregivers' knowledge on childhood pneumonia

\begin{tabular}{lc}
\hline Variables & Frequency (\%) \\
\hline Awareness of pneumonia & \\
Aware & $386(77.2 \%)$ \\
Not aware & $114(22.8 \%)$ \\
Source of information on pneumonia & \\
Health worker & $157(31.4 \%)$ \\
TV/Radio & $8(1.6 \%)$ \\
Older persons in the family, com- & \\
munity & $194(38.8 \%)$ \\
School & $23(4.6 \%)$ \\
Causes of pneumonia (multiple responses) \\
Cold temperature/weather & $335(67.0 \%)$ \\
Germs/dust & $109(21.8 \%)$ \\
Bacteria & $118(23.6 \%)$ \\
Virus & $43(8.6 \%)$ \\
Fungi & $23(4.6 \%)$ \\
\end{tabular}

Signs and symptoms of pneumonia (multiple responses)

$\begin{array}{lc}\text { Fever } & 137(27.4 \%) \\ \text { Chills } & 64(12.8 \%) \\ \text { Headache } & 218(43.6 \%) \\ \text { Wheezing } & 61(12.2 \%) \\ \text { Shortness of breath } & 97(19.4 \%) \\ \text { Stabbing chest pain } & 270(54.0 \%) \\ \text { Convulsions } & 81(16.2 \%) \\ \text { Body weakness/fatigue } & 102(20.4 \%) \\ \text { Chest in drawing } & 102(20.4 \%)\end{array}$

Prevention of childhood pneumonia (multiple responses)

$124(24.8 \%)$

Improves child immune system

$72(14.4 \%)$

Proper nutrition/balanced diet

$70(14.0 \%)$

Exclusive breastfeeding

$43(8.6 \%)$

Proper warm clothing during dry

season

$339(67.8 \%)$

Improve house ventilation

$114(22.8 \%)$

Practice hand washing

$39(7.8 \%)$

Awareness of pneumonia vaccine

Aware

$134(9.0 \%)$

Not Aware

$396(73.2 \%)$

Data presented as frequency (percentage) 
Under-five caregivers' knowledge of Pneumonia Yahaya et al.,

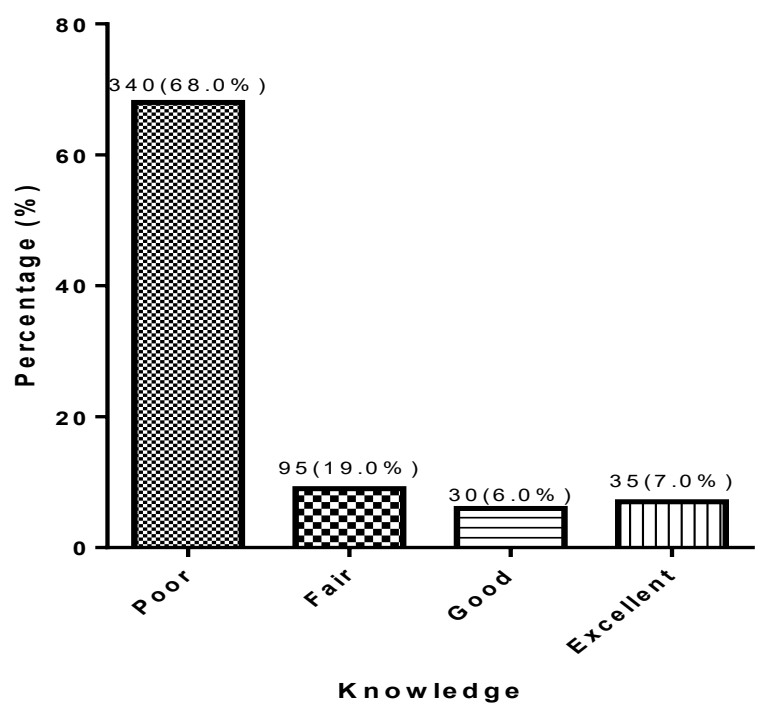

Figure 2: Caregivers' knowledge level on underfive pneumonia pneumonia. This difference was statistically significant $\left(\mathrm{p}\right.$-value $<0.001, \mathrm{df}=6$, and $\chi^{2}=$ 30.333). Majority of the respondents have heard of pneumonia $(77 \%)$ and the main source of information was from older persons in the family or community followed by health workers (Table 3).

The burden of under-five pneumonia was more pronounced in the rural areas $20(8.0 \%)$ when compared to the urban area $13(5.2 \%)$. Analysis using chi square test shows that this difference was statistically significant $\left(\mathrm{p}=0.002, \mathrm{df}=2\right.$, and $\chi^{2}=$ 12.520) (Table 4).

Focus group discussions revealed the terminologies and phrases used to describe pneumonia in this locality as shown in Table 5 below. From the focus group discussions, themes were identified as factors influencing knowledge of pneumonia in the

Table 3: Relationship between caregivers' knowledge of pneumonia and occurrence of childhood (under-five) pneumonia

\begin{tabular}{lccccc}
\hline Caregivers' knowledge of pneumonia & No & Yes & Do not know & Chi square & P - value \\
\hline Poor & 319 & 18 & 3 & & \\
Count & $70.0 \%$ & $54.5 \%$ & $27.3 \%$ & & \\
\% within Occurrence & 76 & 11 & 8 & 30.333 & $<0.001 *$ \\
Fair & $16.7 \%$ & $33.3 \%$ & $72.7 \%$ & & \\
Count & 30 & 0 & 0 & \\
\% within Occurrence & $6.6 \%$ & $0.0 \%$ & $0.0 \%$ & \\
Good & 31 & 4 & 0 & \\
Count & $6.8 \%$ & $12.1 \%$ & $0.0 \%$ & \\
\% within Occurrence & $\begin{array}{l}\text { Excellent } \\
\text { Count }\end{array}$ & &
\end{tabular}

Table 4: Relationship between urbanization (region) and the burden (reported proportion) of under -five pneumonia

\begin{tabular}{llllll}
\hline Region & No & Yes & Do not know & Chi - square & P - value \\
\hline Urban & & & & & \\
Count & 226 & 13 & 11 & 12.52 & $0.002 *$ \\
\% within Urban & $90.40 \%$ & $5.20 \%$ & $4.40 \%$ & & \\
Rural & & & & & \\
Count & 230 & 20 & 0 & & \\
$\%$ within Rural & $92.00 \%$ & $8.00 \%$ & $0.00 \%$ & & \\
\hline
\end{tabular}

Categorical variable compared using chi-square and p-value $<0.05$ considered statistically significant 


\section{Under-five caregivers' knowledge of Pneumonia}

Yahaya et al.,

Table 5. Local illness terminologies used to describe childhood pneumonia

\begin{tabular}{lll}
\hline English name & Local Terminologies & Literal Dictionary Translation \\
\hline Pneumonia & Namoniya & Pneumonia in Hausa language \\
Pneumonia & Ukuluk & Pneumonia in Amawa language \\
Pneumonia & Oweruk & Pneumonia in Jere language \\
Pneumonia & Mokolo & Pneumonia in Dingi language \\
Chest pain & Ciwonkirji & Stabbing pain in the chest \\
Cough & Tari & To expel air from the lungs suddenly and noisily \\
Common cold & Mura & To get a cold or flu \\
Fever & Zazzabi & Increased body temperature \\
Difficult breathing & Kasawan lumfashi & To be out of breath \\
Convulsions & Farfadiya & Sudden involuntary contractions of body muscles \\
\hline
\end{tabular}

Table 6. Codes and themes identified from focus group discussions as influencing the knowledge of caregivers towards under-five pneumonia

\begin{tabular}{llll}
\hline Topic & Codes & Code definition & Theme(s) \\
\hline $\begin{array}{l}\text { Knowledge of } \\
\text { pneumonia }\end{array}$ & $\begin{array}{l}\text { Knowledge transmitted } \\
\text { through generations }\end{array}$ & $\begin{array}{l}\text { Past generations experienced the disease and told } \\
\text { the younger generations of their experiences }\end{array}$ & $\begin{array}{l}\text { Theoretical knowledge } \\
\text { Had experienced the }\end{array}$ \\
& $\begin{array}{l}\text { Individuals in the household and or community } \\
\text { disease }\end{array}$ & $\begin{array}{l}\text { Vivid } \\
\text { had suffered from pneumonia }\end{array}$ \\
& $\begin{array}{l}\text { Campaign by governmental and non- } \\
\text { Dissemination by media } \\
\text { and or health institutions }\end{array}$ & $\begin{array}{l}\text { governmental institutions to create awareness on } \\
\text { pneumonia }\end{array}$ & \\
\end{tabular}

communities: Theoretical awareness and vivid experiences. Theoretical awareness relates to knowledge acquired through third parties, such as awareness programs by health officials both governmental and non-governmental, vaccination campaigns or knowledge passed through generations. It highlights that people are aware of the disease though they have not seen it or experienced it themselves which goes to show the importance of communication about diseases:

"Over the years, pneumonia used to terrify a lot of children here because of the natural cold weather (barmattan), but our parents have had time to tell us about the dangers of the cold and how it relates to pneumonia" (32 years old female rural caregiver).

"We are aware of pneumonia because there are campaigns by health workers concerning how to protect ourselves from the disease by taking advantage of the health centers" (36 year old female urban caregiver).

In contrast, vivid life experiences are the caregivers' direct experience of the disease either in their own children or through someone else's experience in the community, where they see the disease first hand: "T have seen what pneumonia can do to a child. My neighbor lost her children to the disease because at first she did not even know it was pneumonia until it was too late..." (27 year old female urban caregiver).

"I battled with pneumonia as a child so I was very happy when I heard about the introduction of pneumonia vaccines. Now all my children have been vaccinated..." (34 year old male urban caregiver).

\section{DISCUSSION}

In this study, the occurrence of pneumonia as reported by respondents among under-five children was $33(6.6 \%)$ with higher occurrence in the rural areas. This is in line with the report by the NDHS 2013 that childhood morbidity and mortality rates are higher in rural areas than in urban areas where adult education and literacy are relatively low, and with poor socioeconomic and socio-demographic characteristic, differences in access to health services and health information. The adverse effects of pneumonia cannot be over-emphasized given the grave outcomes that come with the condition 


\section{Under-five caregivers' knowledge of Pneumonia}

Yahaya et al.,

because it claims the lives of about 195,000 Nigerian children annually (Madugba, 2015).

Result shows that most of respondents are aware of pneumonia but when pressed further with questions to determine their knowledge level based on causes, risk factors, signs and symptoms of pneumonia, most respondents could not give correct responses. Quite a few number of respondents had knowledge of the signs and symptoms of pneumonia such as fever, chills, wheezing, shortness of breath, stabbing chest pain, fatigue and chest in drawing. The most commonly reported symptom was stabbing chest pain $54 \%$. This is in line with similar studies by Memon et al. (2013) and Ndu et al. (2015). Overall, majority of the respondents had poor knowledge of pneumonia. A similar study in India found $41 \%$ fair knowledge level among mothers of under 5 children (Pradhan et al., 2016).

The uptake of vaccines was found to be low in this study, this is similar to other studies (Aigbokhaode $e t$ al., 2015; Ndu et al., 2015), however the study in Enugu by Ndu et al. (2015), found a higher uptake $(39.7 \%)$ than that reported in this study $(21 \%)$, the difference may be due the poor attitude to vaccination in general by caregivers who are from the northern part of the country. Ndu et al. (2015) however attributed the low uptake to cost of vaccination.

According to Gálvez et al. (2002), knowledge of pneumonia, the perceptions of its causes, the ability to recognize the signs of pneumonia coupled with the behavior of individuals if they were to have a child with the signs may help to build a better understanding of mothers' reaction to child pneumonia and uptake of vaccines.

Most of the respondents interestingly got information about pneumonia from older family or community member, which is an area to be explored in the plan to increase caregiver's knowledge of pneumonia and uptake of vaccines. However, we were not able to assess the association between source of information and uptake of vaccination and health seeking behavior. Ndu et al. (2015), established the fact that source of information influenced uptake of vaccines, those who got their information from health facility were more likely to vaccinate their children than those who got their information about pneumonia from other sources.

Results from this study show that there was a positive association between knowledge of pneumonia and health seeking behavior of caregivers of under five children. This finding is supported by a study which was conducted in 6 sub Saharan African countries including Nigeria by Noordam et al. (2017).

Adequate health knowledge can equip an individual with the right tools and means to avoid a given health condition or at least minimize to a significant level, ones chances of contracting a health condition. Prior knowledge of causes and signs of pneumonia is imperative to the successful mitigation of the adverse health effect of the condition. In the study area, lots of the communities are densely populated, with peculiar climatic conditions such as strong harmattan and numerous industries whose fumes contribute to air pollution, may increase the risk of infection. The occurrence of pneumonia reported in this study was based on responses from the respondents and may not show true picture of the prevalence of pneumonia in the study area. There is the need for a population based study on the prevalence of pneumonia in the study area based on true diagnosis.

\section{CONCLUSION}

The reported proportion of under-five pneumonia in the study was more among the rural dwellers than in the urban area. Though most of the respondents said they were aware of pneumonia, majority had poor knowledge level of the causes, signs and symptoms, prevention and treatment of the disease, which may have resulted in the poor uptake of pneumococcal vaccine. Improving caregivers' knowledge on pneumonia through effective and constant health education of the community members, especially those in the rural area is therefore strongly recommended. 
Under-five caregivers' knowledge of Pneumonia

Yahaya et al.,

\section{COMPETING INTERESTS}

The authors declare that they have no competing interests.

\section{REFERENCES}

Aigbokhaode A.Q., Isah E.C. and Isara A.R. (2015) Health seeking behaviour among caregivers of under-five children in Edo State, Nigeria. South Eastern European Journal of Public Health 3(1).

Gálvez C.A., Modeste N., Lee J.W., Betancourt H. and Wilkins R.L. (2002) Peruvian mothers' knowledge and recognition of pneumonia in children under 5 years of age. Revista Panamericana de Salud Pública 11(2), 99-108.

Gidado S., Nguku P., Biya O., Waziri N.E., Mohammed A., Nsubuga P., Akpan H., Oyemakinde A., Nasidi A. and Suleman I. (2014) Determinants of routine immunization coverage in Bungudu, Zamfara state, northern Nigeria, may 2010. The Pan African medical journal 18(Suppl 1).

Grimwood K., Fong S.M., Ooi M.H., Nathan A.M. and Chang A.B. (2016) Antibiotics in childhood pneumonia: how long is long enough? Pneumonia 8(1), 6.

Madugba A. (2015) Pneumonia kills 195,000 Nigerian children annually, Vanguard. Retrieved

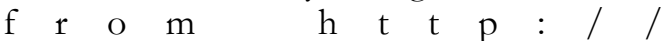
www.vanguardngr.com/2015/07/ pneumonia-kills-195000-nigerian-childrenannually/.

Memon K.N., Shaikh K., Pandhiani B.S. and Usman G. (2013) How do mothers recognize \& treat pneumonia in their children at home? A study in union council Jhudo, District Mirpurkhas. JLUMHS 12(03), 208.

Ndu I.K., Ekwochi U., Osuorah C.D., Onah K.S., Obuoha E., Odetunde O.I., Nwokoye I., Obumneme-Anyim N.I., Okeke I.B. and Amadi O.F. (2015) Danger signs of childhood pneumonia: caregiver awareness and care seeking behavior in a developing country. International journal of pediatrics 2015.

Noordam A.C., Sharkey A.B., Hinssen P., Dinant G. and Cals J.W. (2017) Association be- tween caregivers' knowledge and care seeking behaviour for children with symptoms of pneumonia in six sub-Saharan African Countries. BMC health services research 17(1), 107.

National Population Census(NPC)(2006) Censuses. National and State Population and Housing Tables: 2006 Census Priority Tables Vol 1. Retrieved from http:// population.gov/index.php/censuses. Date accessed April 4th, 2017.

Obinna C. (2015) Harmattan increases risk of infections - experts. Vanguard. Retrieved from http://www.vanguardngr.com.

Pradhan S.M., Rao A.P., Pattanshetty S.M. and Nilima A. (2016) Knowledge and perception regarding childhood pneumonia among mothers of under-five children in rural areas of Udupi Taluk, Karnataka: A crosssectional study. Indian Journal of Health Sciences and Biomedical Research (KLEU) 9(1), 35.

Roca A., Bottomley C., Hill P., Bojang A., Egere U., Antonio M., Darboe O., Greenwood B. and Adegbola R. (2012) Effect of age and vaccination with a pneumococcal conjugate vaccine on the density of pneumococcal nasopharyngeal carriage. Clinical infectious diseases 55(6), 816-824.

Stöppler M.C. (2016) Pneumonia facts. Medicinenet. Retrieved from http:// www.medicinenet.com/pneumonia_facts/ article.htm

Thandar M.M., Kyaw M.P., Jimba M. and Yasuoka J. (2015) Caregivers' treatment-seeking behaviour for children under age five in malaria-endemic areas of rural Myanmar: a cross-sectional study. Malaria journal 14(1), 1.

Tuhebwe D., Tumushabe E., Leontsini E. and Wanyenze R.K. (2014) Pneumonia among children under five in Uganda: symptom recognition and actions taken by caretakers. African bealth sciences 14(4), 993-1000.

WHO (2016) Pneumonia. Retrieved 12/12/2016 http:/ / www.who.int/mediacentre/ factsheets/fs331/en/. 
Under-five caregivers' knowledge of Pneumonia Yahaya et al.,

Wiwa O. and Ojumu A. (2016) Pneumococcal Conjugate Vaccine (PCV) Introduction in Nigeria. In http:// www.clintonhealthaccess.org/. Boston, MA.
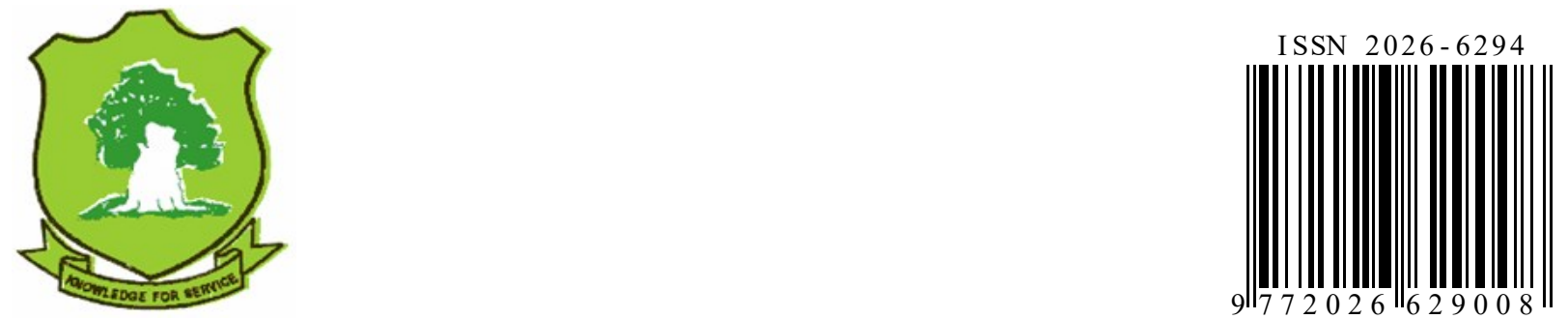